\title{
Study on an Innovation Design Model based on Creative Design Methods and DFSS ${ }^{*}$
}

\author{
Zhigang $\mathrm{Hu}$, Jiashuang Fan, Xianling Qiao and Qiaoran Kong \\ College of Design \& Art, Shaanxi University of Science \& Technology \\ Xi'an, Shaanxi province, China \\ huzhigang@sust.edu.cn,1450630672@qq.com,qiaoxianling@sust.edû.cn.)・ \\ 842245737@qq.com \\ Abstract
}

\begin{abstract}
In order to solve the problems of product innovation design, an innovation model is developed. the five layers innovation design mode integrates the creative methods (cluster analysis, brainstorm, TRIZ, QFD and reliable testing) and the process management method (design for the six sigma). The model take the step as following taking advantage of the $S$ curve of TRIZ evolution theory and design study to indentify the lifecycle stage, using the cluster analysis to study the customers' requirements, using brainstorm to define the most important requirement and the possible solution, utilizing the TRIZ to further explore the creative solutions, utilizing reliable testing to verify the reliable of the final solutions. The five layers model is proved highly effective by the case of Iighting design.
\end{abstract}

Key words: product desig, greative design, method, DFSS, innovation model

\section{Introduction}

Product inpovation has become a key means for enterprises to obtain market initiative. How to scientifically and reasonably using the innovation theory and methods to improve the ability of innovation has become an urgent problem to many enterprises [1]. There are many different kinds of theories and methods of product innovation, each method has its ownemphasis. Among these, the following creative methods is famous: Cluster Analysis (CA), Brain Storm (BS), TRIZ, Quality Function Deployment (QFD), Reliability Testing (RT). Design for Six Sigma (DFSS) is also famous as a management theory.

In order to solve the problem of product innovation design, many scholars has researched on the integration of different theories and methods. Ma has researched on integration of QFD, TRIZ and Design of Experiment (DOE) based on DFSS [2]. Shao has researched on product innovation design method integration of six sigma, QFD and TRIZ [3]. Ji has researched on the product innovative design model based on QFD, TRIZ, CAPP and DOE [4]. Hu has researched on the six sigma Design Method based on integration of QFD, FBS and CDOE [5]. Researches on the integration of various theories and methods have become a hot of product innovation, but the study of innovative design model in the view of whole design process is still deficient.

In order to solve the problems of product innovation design in the view of whole product development process, an innovation design model is developed. The five layers * Sponsored by: Shaanxi science and technology research and development program (2012K07-23), Humanities and social
science fund of Shaanxi University of Science \& Technology (ZX13-18) 
innovation design model integrates the creative methods (cluster analysis, brainstorm, TRIZ, QFD and reliable testing) and the process management theory (design for the six sigma).

\section{Overview of CA, BS, TRIZ, QFD, RT and DFSS}

(1) CA (Clustering Analysis): It is also called group analysis. It is a multivariate statistical method to study the classification. The hierarchical clustering method and iterative clustering method are the mainly two methods of the CA. The method aims at classifying $n$ samples into $m$ clusters under $l$ index, according the individual characteristics of each sample [6-7].

(2) BS (Brainstorm): It is a group or individual creativity technique by which efforts are made to find a conclusion for a specific problem by gathering a list of ideas spontaneously contributed by its member(s). It is a method to eonquer the thinking obstacles based on the psychology and behavioral science. The method is used to help the designers break the restrictions of Thought, professional and individual knowledge, improve the rate of innovative problem solving [8-9].

(3) TRIZ (Theory of Inventive Problem Solving): the theory aims at solving the inventive problem. It was developed By Genrich Altshuler and his colleagues in the former USSR starting in 1946, after examining over 2 million patents all over the world. Its core is the evolution theory of techmologye The main tools to analyzed and solved problem are Contradiction Matíx, Conflict resolution principle, principle of invention, substance field analysis, stanđard solution and effect [10].

(4) QFD (Quality Funetion Deployment): It is a customer oriented product development methods, based on the house of quality (HOQ). Through the correlation matrix, the relationship matrix and the customer's weight matrix, the QFD calculates the weight of each contradiction solution, obtains the optimal contradiction solution [11].

(5) RT (Reliability Testing): It's general term for following reliability experiments: understanding, analyzing, improving and evaluating the solutions. The purpose of reliability testing is to discover potential problems with the design as early as possible and, ultimately, make sure that the system meets its reliability requirements.

(6) DFSS (Design for Six Sigma): It is an effective method to improve product quality and reliability, reduce the cost and shorten the development cycle. At present, the design of innovative products usually refers IDDOV process: identify, definition, design, optimize, verify [12-13].

\section{The Relationship between CA, BS, TRIZ, QFD, RT and DFSS}

\subsection{Study on the Complementary Relationship between CA, BS, TRIZ, QFD and RT}

CA, BS, TRIZ, QFD and RT are the famous methods in the engineering field. They can be used individually or group to solve certain engineering problem. In fact, there is a closely relationship between them. BS finds the problem to be solved, based on Cluster Analysis (CA) of the customer data. BS can identify "what to do", but there is no answer about "how to do". TRIZ is used to find "how to do". TRIZ is also a effective method to solve the contradictions and conflicts between the requirements and the solutions. But TRIZ cannot find "how to better". QFD can calculate the weight coefficient of 
each solution, select the optimal solution scientifically and flexibly [11]. RT is used to test the solutions whether they are reliable. The relationship between these methods is shown in Table 1. The analysis indicates that, CA, BS, TRIZ, QFD and RT can well support each other. The group of these methods names method set. Integrating method set with a reasonable process will produce a great creativity.

Table 1. Relationship between CA, BS, TRIZ, QFD and RT

\begin{tabular}{|c|c|c|c|}
\hline $\begin{array}{l}\text { Innovative } \\
\text { Methods }\end{array}$ & Advantage & Disadvantage & Solution \\
\hline $\mathrm{CA}$ & Sorting perplexing data & Cannot find problem & \\
\hline BS & Find essential problem creatively & Can't solve tl & $\mathrm{Z}$ \\
\hline TRIZ & Solve the problem rationally & Can't & QFD \\
\hline QFD & $\begin{array}{l}\text { select the optimal solution } \\
\text { scientifically and flexibly }\end{array}$ & 1) & RT \\
\hline RT & Reliable judgment & $\begin{array}{c}\text { Lack of fundamental solution } \\
\text { options }\end{array}$ & Integration \\
\hline
\end{tabular}

\subsection{Study on the Relationship between Method Set and DFSS}

DFSS (Design for Six Sigma) i\&proved to ke a scientific management process. And it's usually divided into five stages: ideptification, definition, design, optimization, verification. The five metheds in the method set well Correspond to the five stages. The detail information is shown in Table 2

Table2. The Relationship between Method Set and DFSS

\begin{tabular}{|c|c|c|c|c|c|}
\hline $\begin{array}{c}\text { DFSS process } \\
\begin{array}{c}\text { TRIZ evolution } \\
\text { theory }\end{array}\end{array}$ & Identification & Definition & Design & Optimization & Verification \\
\hline CA、BS & & & & \\
\hline TRIZ & & & $\sqrt{ }$ & & \\
\hline QFD & & & & $\sqrt{ }$ & \\
\hline RT & & & & $\sqrt{ }$ \\
\hline
\end{tabular}

\section{Five Layers Innovation Design Model based on Method Set and DFSS}

The innovation model based on the method set and DFSS is shown in Figure 1. The model has five layers according to the DFSS manage process: identification layer, definition layer, design layer, optimization layer and verification layer. 


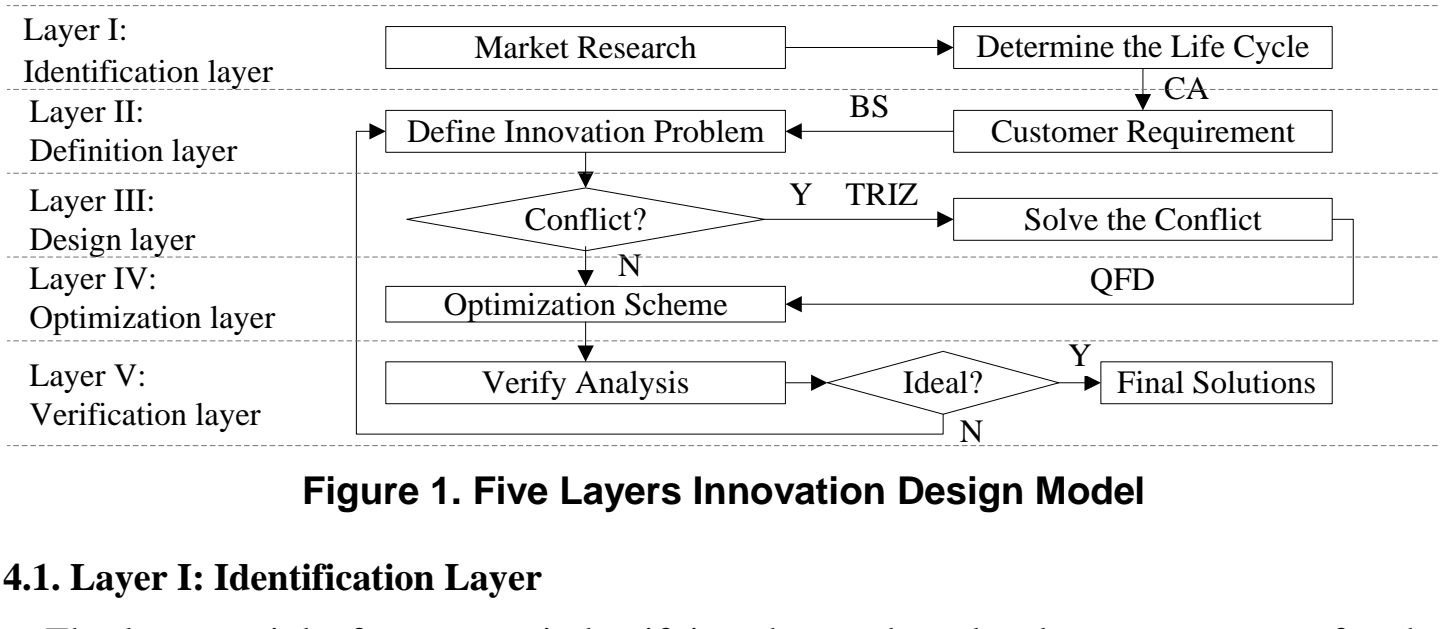

The layer mainly focuses on indentifying the productydevelopment strategy for the target product. Collected the product information, analyzed the level of product technical maturity using the $S$ curve of TRIZ evolution theory [17], the product lifecycle stage $(P)$ is work out. According to the lifecyele theory, the product lifecycle is divided into four stages: introduction $\left(p_{1}\right)$, growth $\left(p_{2}\right)$, maturity $\left(p_{3}\right)$ and decline $\left(p_{4}\right)$. That is $P=$ $\left(p_{1}, p_{2}, p_{3}, p_{4}\right)$. Referring articles [19-20], the product developing methods contains: structural parameters optimization ( $\left.m_{1}\right)$, functional parameters optimization $\left(m_{2}\right)$, product improvement $\left(m_{3}\right)$ and new product development $\left(m_{4}\right)$ Corresponding to the different product lifecycle. That is $M=\left(m_{1}, m_{2}, m_{3}, m_{4}\right)$. The Correspondence between $P$ and $M$ is shown in Figure 2.

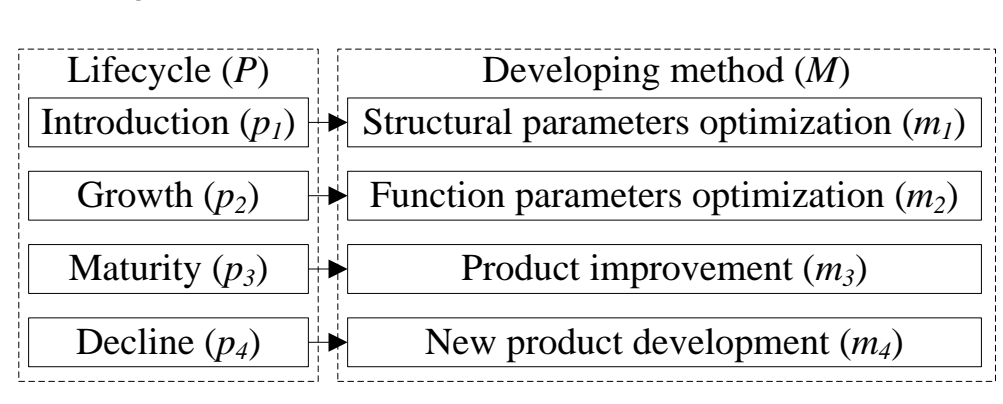

Figure 2. The Correspondence between $P$ and $M$

The product strategy $(S)$ is a combination of the product lifecycle and the product developing method. The calculation equation is shown in equation 1 . By this way, the best strategy $S$ is identified.

$$
S=\left(\begin{array}{llll}
p_{1} & p_{2} & p_{3} & p_{4}
\end{array}\right)\left(\begin{array}{l}
m_{1} \\
m_{2} \\
m_{3} \\
m_{4}
\end{array}\right)=P \cdot M^{T}
$$

Where $p_{i}=(0,1),(i=1,2,3,4)$. When the target product lifecycle is at stage $p_{i}$, then $p_{i}=1$. Otherwise, $p_{i}=0$. 


\subsection{Layers II: Definition Layer}

Using CA to analyze the customer requirement and BS to deal with the requirement, this layer aims to define innovation questions and solutions. According to the characters of product developing strategy $S$, questionnaires are developed to obtain customers requirements. A number of experts is asked to study the customers requirement using CA. The customer's requirements contain: direct requirements of users or purchasers $\left(r_{1}\right)$, indirect requirements of medias or enterprises $\left(r_{2}\right)$, basic requirements of customers $\left(r_{3}\right)$, expected requirements $\left(r_{4}\right)$ [21]. Let $\mathrm{R}=\left(r_{1}, r_{2}, r_{3}, r_{4},\right)$. In the space $R$, all the customer's requirements are clustered into certain groups using CA. According to the methods of CA, Each group is named by the most representative requirement.

According to the groups, the experts are invited to take part in BS conference to define the essential questions and search the solutions.

\subsection{Layer III: Design Layer}

The main task of the layer is to solve the conflicts of customer's requirements or solutions using TRIZ. There are two conflict's types in TRIZ theory: technical conflict and physical conflict. The experts are invited to judge whether there are conflicts between the requirements and solutions. The conflicts ate represented by character $c_{i}$, and Non-conflicts are represented by character $n_{j}$. Let $C=C\left(c_{i}\right), N=N\left(n_{j}\right)$. $C$ or $N$ is the set of all conflicts or non-conflicts. The experts categorize the $c_{i}$ into two conflict's types. To the technical conflicts, 39 general ergineering parameters are used to describe the conflicts, 40 invention principles are used to solve the conflicts $\left(d_{1}\right)$; To the physical conflicts, four separation principles are used to solve the conflicts $\left(d_{2}\right)$. In addition to these, the effects database $\left(d_{3}\right)$ and Substance-field model With 76 standard solutions $\left(d_{4}\right)$ can also use to solve the eonflicts. $D$ is used to describe the solutions set of conflicts, let $D=\left(d_{1}, d_{2}, d_{3}, d_{4}\right)$.

\subsection{Layers IV: Optimization Layen}

The set of possible requirements solutions contains non-conflicts solutions set $N$ and conflicts solutions set $D$. Under the restriction of the development cycle, cost and actual situation of enterprises(QFD is used to choose which solutions are most suitable. As the result, optimized solutions set is worked out, and represented by $S O\left(s o_{i}\right)$.

\subsection{Layers V: Verification Layer}

Using R To verify the $S O\left(s o_{i}\right)$ whether it's reliable or not is the layer's task. In the layer, number of questionnaires and experiments is conducted to make sure the $S O\left(\operatorname{so}_{i}\right)$ is characterized by higher cost performance, higher rate of success, lower maintain cost and easier manufacture. If the test is not passed, go back to the layer II, and repeats the steps. Otherwise, the $S O\left(s o_{i}\right)$ is the suitable solutions set for the target product, and can be carried out immediately.

\section{Case Study}

Taken the example of the lighting design to verify the five levels innovation design model based on the method set and DFSS. 
(1) Identification layer: Based on the design study and TRIZ evolution theory, the lighting product is at maturity stage $\left(p_{3}\right)$. The developing method is product improvement $\left(m_{3}\right)$. So, the output of layer I is: $S=P \cdot M^{T}=$ product improvement.

(2) Definition layer: According the lighting and it's maturity stage, a questionnaire was made to survey the customer's requirements. 200 lighting buyers were asked to fill the questionnaires, as the result, 186 questionnaires was valid. After cluster analysis by SPSS (Statistical Product and Service Solutions software, IBM), 6 groups of requirements were obtained. The result is shown in the table 3.15 professionals was invited to take part in the BS conference. Finally, the emotional design was found to be the key requirement of the lighting design.

Table 3. The Representative Requirements of Customer after CA

\begin{tabular}{|c|c|c|c|}
\hline Group I & Novel and unique style & Group IV & Creative and eas y operation \\
\hline Group II & Meeting the need of emotion & Group & Excellent and dable material \\
\hline Group III & Soft and uniform light & Group VI & Assemble and maintain easily \\
\hline
\end{tabular}

(3) Design layer: To the problem of emotion 1ighting đesign, 40 invention principles of TRIZ solution tools were used to solve the problem (table 4). Figure 3 is the design sketch.

Table 4. The Application of 40 Invention Principles in Lighting Design

\begin{tabular}{|c|c|c|}
\hline $\begin{array}{l}\text { Invention } \\
\text { Principles }\end{array}$ & & Application \\
\hline $\begin{array}{l}\text { Principle } 1 . \\
\text { Segmentation }\end{array}$ & Divided an o, & $\begin{array}{l}\text { Divided lighting into light source, lighting } \\
\text { base and rotate shaft. }\end{array}$ \\
\hline $\begin{array}{l}\text { Principle } 3 . \\
\text { Local Quality }\end{array}$ & $\begin{array}{l}\text { and/or complementary useful } \\
\text { and object fulfill a }\end{array}$ & $\begin{array}{l}\text { Light bar: illumination. } \\
\text { Shaft: folding, switch and control the } \\
\text { direction of the light. } \\
\text { Base: support. }\end{array}$ \\
\hline $\begin{array}{l}\text { Principle } 6 . \\
\text { Universality }\end{array}$ & $\begin{array}{l}\text { Make a part or object perform multiple } \\
\text { functions, eliminate the need for other } \\
\text { patts }\end{array}$ & $\begin{array}{l}\text { The shaft performs } 3 \text { functions: the switch, } \\
\text { light direction controller and style } \\
\text { transformation. }\end{array}$ \\
\hline $\begin{array}{l}\text { Principle } 8 . \\
\text { Anti-weight }\end{array}$ & $\begin{array}{l}\text { To compensate for the weight of an } \\
\text { object, merge it with other objects that } \\
\text { provide lift }\end{array}$ & $\begin{array}{l}\text { There is a set of friction pads in the shaft, } \\
\text { in order to balance the weight of the light } \\
\text { bar when it is folded. }\end{array}$ \\
\hline $\begin{array}{l}\text { Principle } 15 .) \\
\text { Dynanics }\end{array}$ & $\begin{array}{l}\text { Allow (or design) the characteristics of } \\
\text { an object, external environment, or } \\
\text { process to change to be optimal or to } \\
\text { find an optimal operating condition. }\end{array}$ & $\begin{array}{l}\text { The light bar can stay in any position } \\
\text { without any other operation. } \\
\text { The degree of illumination is determined } \\
\text { by the number of folded light bar }\end{array}$ \\
\hline $\begin{array}{l}\text { Principle } 17 . \\
\text { Another } \\
\text { Dimension }\end{array}$ & $\begin{array}{l}\text { If an object contains or moves in a plane, } \\
\text { consider use of dimensions or movement } \\
\text { outside the current plane }\end{array}$ & $\begin{array}{l}\text { Transform 2D light bars into 3D light bars } \\
\text { by folded them. } \\
\text { Transform the static lighting into style } \\
\text { changeable lighting. }\end{array}$ \\
\hline
\end{tabular}




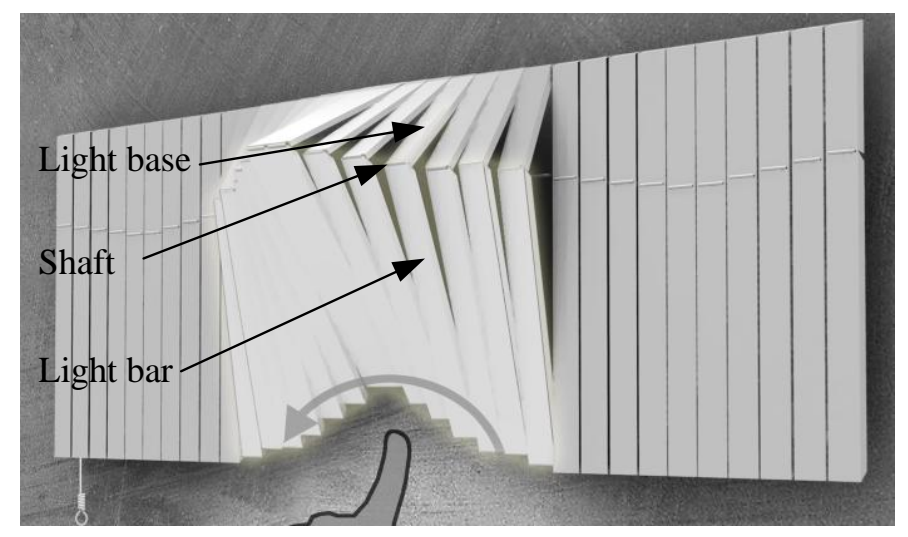

Figure 3. Lighting Design Sketch

(4) Optimization layer: Taken the cost, process and cycle into account, QFD was used to optimize the solution set. In this case, besides the Operating mode needed to be improved in order to meet the need of emotion design, other solutions were feasible. The final design is shown in Figure 4.

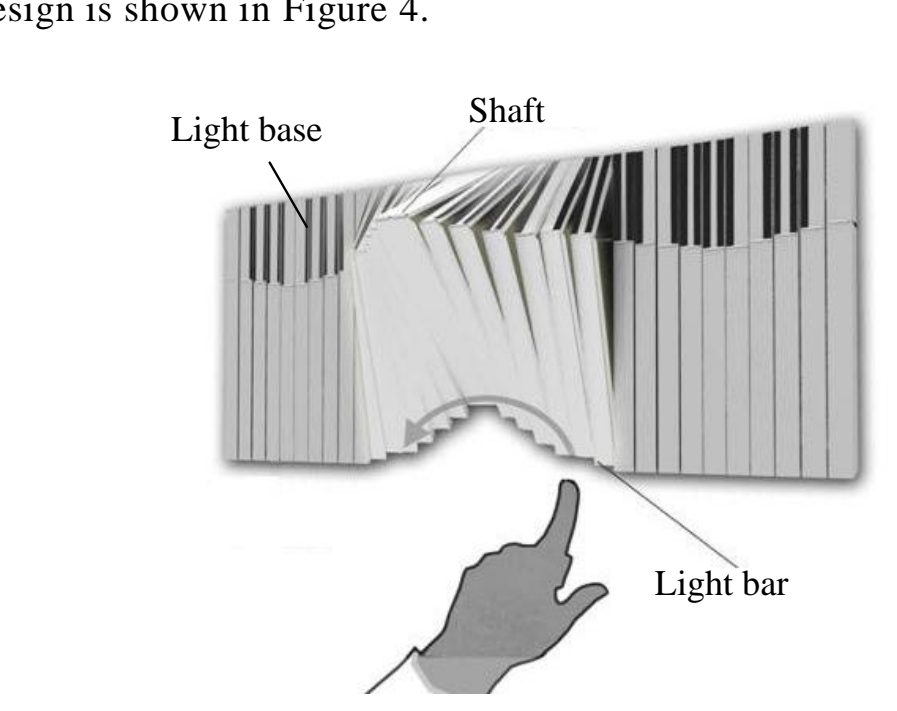

Figure 4. Final Design

(5) Verification layer: A series of experiments was conducted, and the result showed that the design was reliable.

\section{Conclusion}

In order to solve the problems of product innovation design, the study develops a innovation design model, which integrates the creative method (AC, BS, TRIZ, QFD, $\mathrm{RT}$ ) and the process management theory (DFSS). The five layers model is proved highly effective by the case of lighting design. The study is a attempt of innovation methods integration in the view of the whole product developing process. And the research result will provide method reference for other innovative design. 


\section{References}

[1] R. Tan, "Innovative design", Beijing: Mechanical Industry Press, (2000).

[2] Y. Ma and Z. He, "Research of Integration Frame Based on QFD, TRIZ and DOE", modular machine tool and automatic manufacturing technique, vol. 1, (2007).

[3] Y. Shao, X. Du and X. Tang, "Product innovation design method based on 6 Sigma, QFD, TRIZ integration [J]", System Engineering, vol. 4, (2011).

[4] G. Ji, Y. Li, Y. Hu and D. Nie, "Product innovation design model integrated with QFD,TRIZ,CAPP and DOE [J]", Machinery Design and Manufacture, vol. 10, (2010).

[5] Y. Hu, Y. Li, G. Ma, "A Design Method of Six Sigma Based on Integration Mode", machine design and research, vol. 1, (2009).

[6] H. Tian, "On Evaluation Method Integrating AHP and Classified Analysis", East Ohina economic management, vol. 08, (2007).

[7] H. Wu, "Application of multivariate statistical analysis", Henan provinge and statistics, vol. 03, (2003).

[8] BAUGARTNER, "The step by step guide to brainstorming”, http//ww whipb.com/creative/, (2003).

[9] X. Zhu, "Application of brainstorming in mall management decision", market modernization, vol. 09, (2009).

[10] J. Ding, "The Theory of Solving Invention Problem-Review of TRIZ", science of science and management of s. and t. , vol. 11, no. 53, (2004), p. 60.

[11] X. Qiao, Z. Hu and Y. Liu, "Study on improvement design decision of sewing product base on house of quality”, manufacturing automation, vol. 03, (2011).

[12] Marin, "Six Sigma management", Beijing: People publishing house, (2004).

[13] Z. He, Z. Liang and F. Zou, "6 $\sigma$ Design Mode and Its Application", construction machinery and equipment, vol. 7, (2006).

[14] Q. Dai and M. Qi, "Innovation model design Researck based on the combination of six sigma and TRIZ", Studies in Science of Science, vol. 2 (2009).

[15] X. Liu, R. Tan and L. Yao, "Application Researoh on Integrated Process Model for the Conceptual Design of Product Innovation”, Chinese journal of mechanical engineering, vol. 9, (2008), pp. 154-162.

[16] E. A. Averboukh, "Six Sigma Trends: TRlZ Six Sigma for Cost Reduction: Strategic Breakthrough Training Based Project", TRIZ Journal, (2006) Júly, http://www.triz-journal.com

[17] Q. Huang, X. Zhouand Z. Yang, "Reviey on the Research of TRIZ Technological Evolution Theory and its Application [0]. Science of science and management of s. and t., vol. 4, (2009).

[18] X. Zhao, "The theory of technølogy innovation (TRIZ) and application", Beijing: Mechanical Industry Press, vol. 4 , no. 129, (2010). p. 33

[19] S. Li and J. Mou, "A pesearch for Evolutionary Process based on TRIZ Evolution Theory", Journal of Changchun University of Science and Technology, vol. 09, (2009).

[20] Y. Han, "Game Analysis of enterprise development strategy", Zhejiang University, (2008).

[21] Z. Jing, Cústomer requirements identification and fuzzy clustering recognition method", Southeast Universit,$(2005)$.
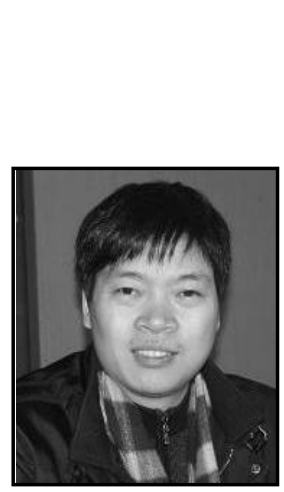

\section{Authors}

Zhigang Hu, He received her M.E. in Industrial Design (2003) from University. Now he is full professor of industrial design at college of art and design, Shaanxi University of Science and Technology. Since 2006 he is dean of the industrial design department. He current research interests include ergonomics and industrial design, computer-aided industrial design. 


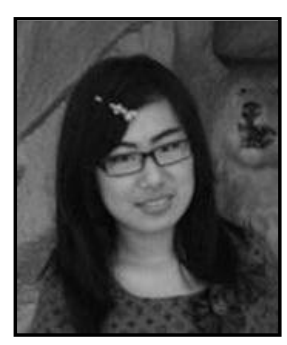

Jiashuang Fan, She received her B.A. in Art Design (2012) from Yangtze Normal University. Now, she is a post-graduate Shaanxi University of Science and Technology. Her current research interests include ergonomics and industrial design, computer-aided industrial design.

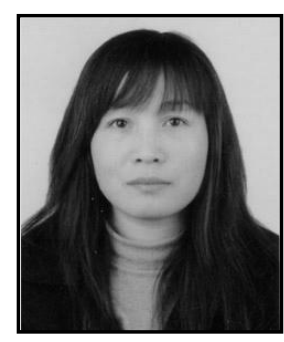

Xianling Qiao, She received her M.E. in Industrial design (2005) from Shaanxi University of Science and Technology. Since 2011/she is a post-graduate tutor in the art field. Her current researeh interests include ergonomics and industrial design, computer-aided industrial design.

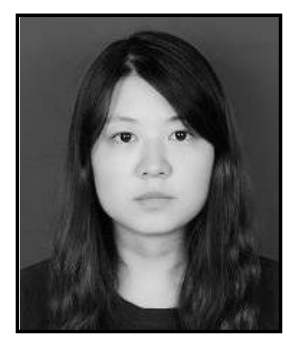

Qiaoran Kong, She received her $\vec{B}$. A. in Industrial design (2011) from Shaanxi University of Science and Technology. Now, she is a post-graduate in Shaanxi University of Science and Technology. Her current research interests include ergonomics and industrial design, computer-aided industrial design.
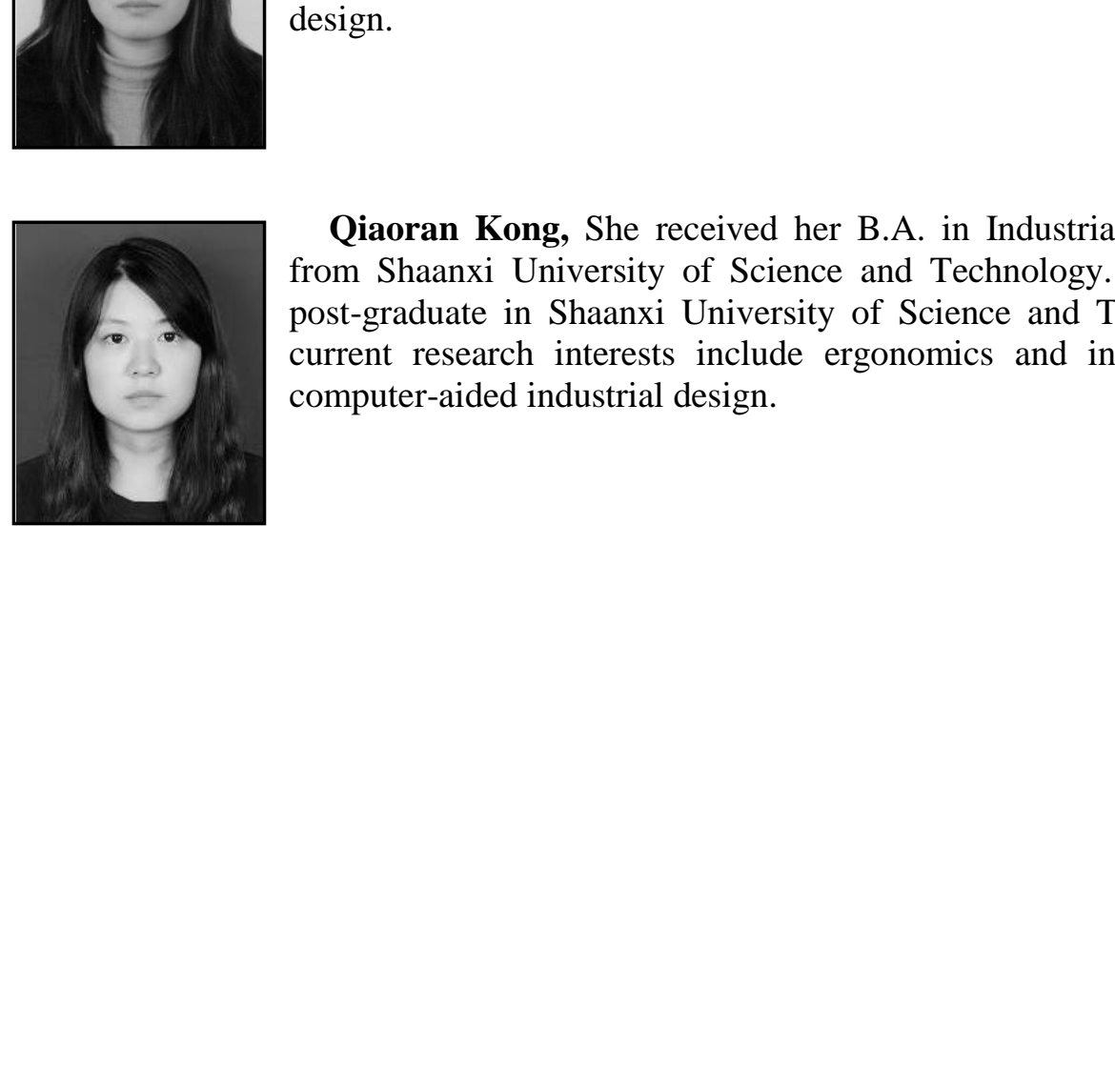
International Journal of Multimedia and Ubiquitous Engineering Vol.9, No.6 (2014)

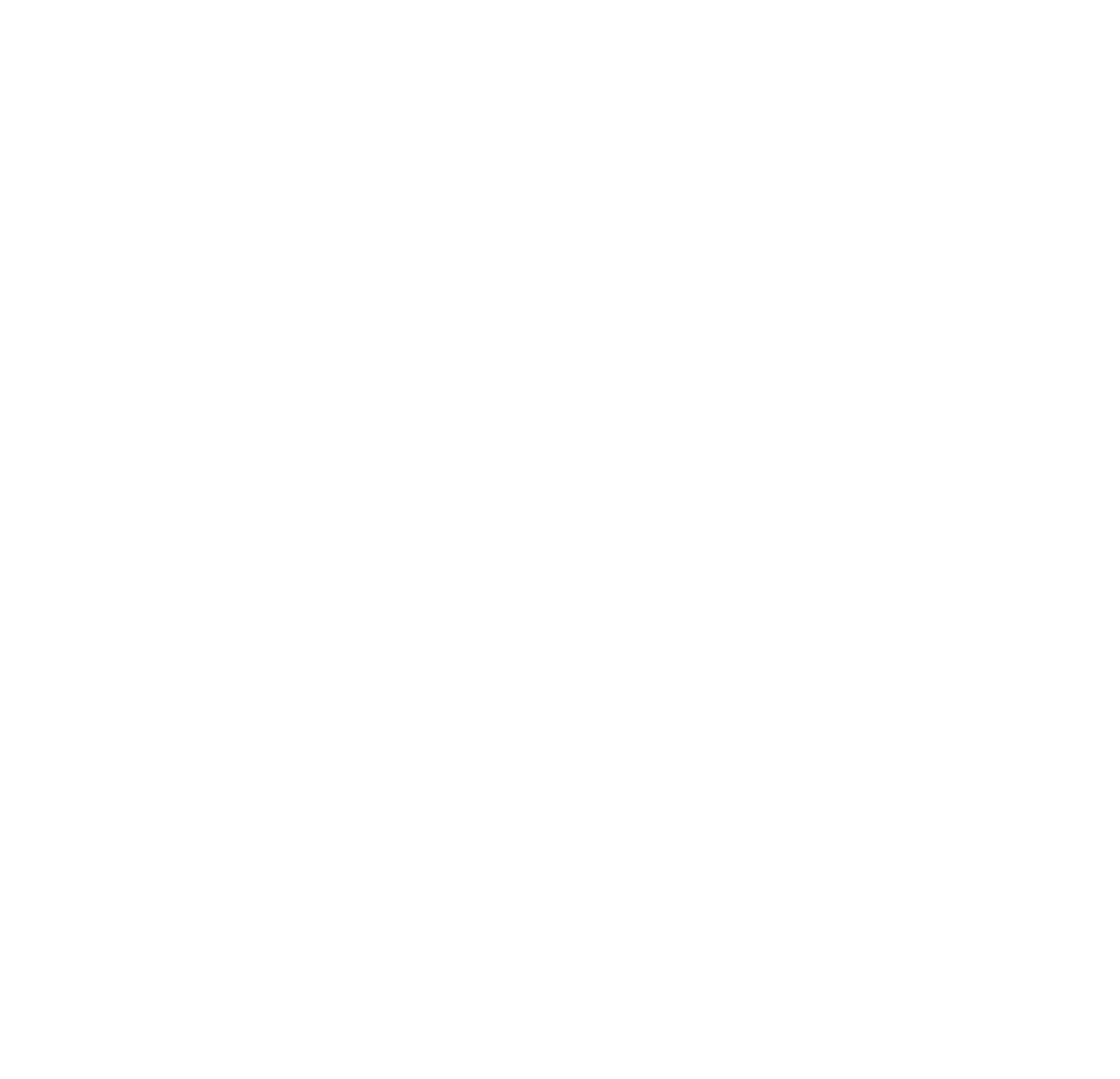

